\title{
Institutional Challenges In Managing County Government Resources In Kenya
}

\author{
William Sagini Oribu \\ School of Business and Economics, \\ Mount Kenya University, P O Box 342 - 01000, Thika, Kenya.
}

\begin{abstract}
In 2010 the Government of Kenya promulgated a new Constitution, articulating a devolved-system of Government entailing a National Government and County Governments. As a key pillar to the constitution of Kenya, devolution seeks to bring governance closer to the people. Kenyans are therefore looking at the county governments to derive the required change in the country. However, fundamental challenges have continued to dog the Counties including irregular or delayed disbursement of devolved funds from the national Exchequer; low revenue collection levels from local sources; weak and uncoordinated planning and execution among others. This has led to several stalled projects; indebtedness to suppliers; inadequate capacity at the county level to effectively and efficiently perform the devolved functions; inadequate financial resources among others. Although there are opportunities for Foreign Direct Investment and capital inflow; Public-Private Partnerships; Grants; Exchange programs; and wider markets for the local products, that the Counties need to explore and pursue, most of them are not in a position to sustain themselves. The purpose of this paper is to review the Institutional and Legal frameworks as provided by the Constitution of Kenya using the business sustainability model of the seven Ps (i.e. Preparation, People, Processes, Preservation, Place, Product and Production). It is hoped that the paper will form a conceptual framework to inform future county Government's strategic decisions in order to utilize grants from development partners for the improvement of their citizens welfare. Further the paper will inform policy makers and development partners on fundamental areas that may need to be looked at in order to ensure effective utilization of available resources.
\end{abstract}

Keywords: Development, Effective, Efficiency, Equitable, Sustainability and Welfare.

\section{INTRODUCTION}

On 27th August 2010 a new constitution was promulgated in Kenya that would change the governance landscape. It stipulated the dissemination of both the political and economic resources from a centralized system of governance to the people in the grassroots. This process was called devolution and it provided a clear administrative framework between the National and County 
Government. The purpose was to encourage a bottom-up approach of participation in development as opposed to the traditional top-down approach of governance which had led to the marginalization of some regions in terms of development. Devolution therefore envisages a relationship of both mutuality and independence. However, over ten years since promulgation of the new constitution, a good number of Kenyans are still not aware of the functions of the national and county governments. This has led to criticism for not receiving the expected services despite the fact that there is the separation of powers and allocation of functions between the National Government and the County Government. This has led the County Governments feel getting the short end of the stick.

This paper presupposes that County Governments are businesses that are in their infantry thus a need to adopt the seven P's of business efficiency. The seven P's are group into; i) building the application (i.e. Preparation, People, Processes, and Preservation) and ii) taking action (i.e. Place, Product, and Production). For purposes of this paper the seven requirements of business efficiency will be merged into one group since they are close relationships as follows: i) Preparation/Place (refers to creating awareness, examining needs and improving the environment where activities are taking place; ii) People/Product (refers to getting employees involved, keeping them motivated and increasing the efficiency of goods are services demanded by the citizens); iii) Processes/Production (refers to efficiency related work philosophies and cultures, and cutting waste and costs in the process of serving the citizens); and iv) Preservation (refers to measuring progress, staying on track and making continuous improvement).

\section{LITERATURE REVIEW AND POLICY/LEGAL FRAMEWORK}

\section{Preparation and Place:}

Before beginning the process of becoming more efficient, and reducing waste of the scarce resources, it is important to; i) learn what efficiency entails, ii) articulate why the pursuit of efficiency is important, and iii) set the groundwork that will instill service providers with reasons, enthusiasm and support necessary to initiate efficiency improvements on their own [(Scott, 2008; Deal, T. \& Kennedy, A. (1988)]. This will avoid confusion, suspicion, disorganization and dwindling motivation as well as wasted time and efforts. Efficiency will therefore help in: i) Achieving optimal outputs with minimal input; and ii) Obtaining one hundred percent value from procurements and project implementation. The obstacles that lead to inefficiency include; Lack of awareness, nonacceptance, the cost myth, the small time saving notion, skepticism, social loafing, let's wait and see attitude, not embracing continuous improvements, job loss argument among others. In order to achieve efficiency supervisors must choose between the choices of management theory (i.e. either to serve customers or serving the appointing authority). Employees may opt to serve the appointing authority in cases where there is blurred distinction between the arms of government and independent bodies [(Harrison, R. (1972), O’Reilly, C., Chatman, J. \& Caldwel, D. (1991); Schein, E. (1990)].

Article 233 of the Kenya constitution clearly stipulates that there be established a Public Service with stipulated functions and powers. Section 57 of the County Government Act 2012 stipulates that there be established a County Public Service Board which shall be: a) a body corporate with perpetual succession and b) capable of suing and being sued in its corporate name. Section 59 of the same act goes ahead to specify the functions and powers of the County Public Service Board to be: i) establishing and abolishing offices in its public service; ii) appointing persons to hold or act 
in those offices; iii) confirming appointments; iv) exercising disciplinary control over and removing persons holding or acting in those offices among others. In this regard, there should be organizational structures in place which stipulate the number of staff in each category for all departments in the County. Further, Article 232 of the Kenya Constitution indicates national values and the principles of public service

In order to establish efficiency as an objective goal setting must be specific, acceptable, measurable and time bound. Providing good feedback produces more results than saying anything (Locke, 1968). This calls for continuous monitoring of activities across the county thus the Management by Working around concept becomes an ideal option.

For achievement of workable objectives there is need to create a vision, decide on the mission, break the mission statement down into achievable objectives, and formulate the objectives to achieve the objectives. Although this may be contained in the respective governor's manifesto the constitution of Kenya call for citizen participation in deciding what they require. The constitution provides that in exercising its powers or performing any of its functions, a county government shall ensure efficiency, effectiveness, inclusivity, and participation of the people. The principle of citizen participation is enshrined in the County Governments Act 2012 section 87.

Section 110 of the County Government Act 2012 requires that County Governments draw a Tenyear Spatial and Sector Plans from where Five-year Departmental Strategic Plans are drawn as per section 109 of the County Government Act 2012. In line with section 126 of the Public Finance Management Act 2012, Annual Development Plans are then derived from the Five-year Departmental Strategic Plans. These are followed by Work Plans, Annual Budgets, Performance Contracting and Staff appraisals in that order. Monitoring and evaluation together with Reporting and learning (rectifying where targets have not been met) is then conducted either; weekly, monthly or quarterly as may be considered appropriate.

\section{People and Product}

In order to improve in efficiency, all employees should be involved in all the processes involved in service delivery in order to have seamless communication to the customers. A customer as everyone that an organization services thus can be classified into External and internal (Oakland, 1993). Good customer service begins with good ethics and includes common etiquette, always telling the truth, sincere attempts at quality and giving immediate attention (Baud, 1991). The use of ten customer commandments as taught by Mahatma Gandhi will help achieve the above (Scott, 2008). Chapter six of the constitution of Kenya stipulates the requirements of leadership and integrity with Article 75 stating how state officers are expected to conduct themselves.

In order to manage change one must: Prepare for it by unfreezing existing behaviors, changing existing behavior, and freezing new behaviors by reinforcing new work practices with rewards (Cole, 1991 \& McClelland, 1961). In order to motivate employees there is need to embrace delegation, make empowerment work, avoid establishment of a police state and be consistent in providing feedback and that momentum must be maintained [(Herzber, 1968 \& Caudron, 1995)].

For an organization that seeks to improve efficiency and reduce waste, there is need to arrange employees into teams in order to produce synergy (Scott, 2008). These should be cross sectional, 
problem solving or self-managed. Teams will matter most when they are as professional and productive as possible. For efficiency to happen, the individuals in any one team are aware of the necessity and purpose of the team in which they belong [Oakland, (1993); Bisoux, T. (2005); Drucker, P. (1988); Fiedler, F. E. (1992); and Hersey, P. \& Blanchard, K. H. (1988)]. Further there is need to identify the people to be included, have a plan of action, prepare well for team meetings and have the necessary tools. Effective team will have practiced on their presentations, have known each other's strengths and weaknesses, brainstorm after meetings and have follow-up procedure in place. This requires that employees should have had a training in interpersonal skills (Robbins \& Hunsacker, 1996).

The importance of carefully designing the product before hand ensures that; its resources can be optimized and maybe re-used in case of a closed loop system (Beitz, 1993). Section 87 of the County Governments Act states the principles of citizen participation. It implying that it is the citizens in a given county who should decide on how and when they prefer a service to be delivered through a democratic process.

Schedule four of The Constitution of Kenya stipulates clearly how the functions are to be distributed between the National Government and the County Governments. Further the fourth schedule of The Transition to Developed Government Act (GoK, 2012) indicates that the authority was transition the functions in two phases. The purpose of this requirement was to ensure that the County Governments have enough time to train its people on the tasks ahead.

\section{Processes and Production}

Processes and Production deal with a series of progressive, interrelated steps or actions from which an end result is attained. Every process should be aimed at total and systematic elimination of loss of any resource that does not lead directly to value addition (Huber, 1975). In order to achieve this, there is need for comparative networking, insistence on quality, handling of conflicts arising from anticipated changes among others. Management should dig for the sources of disagreement and know the personalities and interests of the players (Paunds, W. 1969). When conflict arises there are five typical options that develop thus: avoidance, accommodative, forcing own way, comprise or collaboration [(Filley, (1975) \& Simon, (1947)].

Article 10 of the Constitution of Kenya stipulated the national values and principles of governance that need to be followed Section 116 of the County Government Act 2012 states that a county shall deliver services while observing the principles of equity, efficiency, accessibility, nondiscrimination, transparency, accountability, sharing of data and information, and subsidiarity. Section 117 of the same act proceeds to give the standards and norms of public service delivery. In this regard, there have been acts of parliament and regulations thereof to show how employees should go about specific tasks.

\section{Preservation}

Preservation involves creating an environment that locks into place programs and practices that are successfully implemented, staying in top of new developments and improving motivation and momentum so that new success can be achieved (Scott, 2005). It involves making and living with decisions. Both problem solving and decision making involve recognizing that the processes and outcomes of any decision is influenced three different mind sets thus: avoidance, battling the 
problem or problem prevention (Huber, 1975). Two approaches are normally applied in decision making: i) Systematic (maximizing) where decision challenges are addressed in a rational and analytical fashion, ii) Imitative (Satisfying) which allows more flexibility and spontaneity.) The tips for optimal solutions as follows: believe in own creativity, encourage nonconformity (i.e. allow differences to be presented), reach out beyond personal specialization, search for more than one right answer, take time to think, and don't be afraid of trial and error. It is important to involve juniors if decisions have to be follow to the letter (Roger von Oech, 1986). In case decisions slow down or fail the following actions can help overcome the problem (Hagarth et al., 1994): i) Ensure everyone knows what is expected of them and what needs to be done; ii) Make a "To Do" list to help employees focus on one goal at a time and affirm that the progress is being made; iii) For delegation of tasks and in order to allow employees to come up with their own solutions; iv) Compare what was accomplished to what was expected (Agor, 1989); and v) If a task seems too daunting move on to the next item on the "To Do" list. Always ensure that records are kept on all that is being done.

Article 177 of the Constitution of Kenya provides for the County Assembly which will be elected for a term of five years to provide county legislation, Oversight and representing the people in the respective wards. In their oversight role, members of the county assembly are entitled to assess any records they require. Various legislations and regulations have been formulated by acts of parliament on how ways and how long various records should be kept. Further section 3 of the National Government Co-ordination Act (2013) provides the objectives of the action which is to: a) provide for the co-ordination and administration of the national government functions; and b) provide for the establishment of an administrative and institutional framework at the National, County and decentralized units to ensure access to national government services in all parts of the republic of Kenya among others.

The United Nations Development Program report on the devolution pillars and lessons learnt (Mugore, J. L. M., 2015) it is recommended that for effective support for devolution in Kenya there is need to: understand the politics of devolution; situate support in the county governments; prioritize projects that support decentralization; and balance national government's functional review of sectoral ministries with the county government proposal for the decentralization of the same function.

\section{CONCLUSION}

The paper has shown that in the context of seven requirements of business efficiency there is sufficient legal framework for the implementation of efficient, sustainable and waste management policies for the development of County Governments. There are also provisions in the constitution of Kenya for efficient and timely service delivery to the citizens. The problem that may be causing the misunderstanding could be institutional frameworks which may need to be addressed by the specific counties. This is on the understanding that each of the forty seven counties will be operating from different environment and culture which may need to be looked at the local level.

It is however important to note that there would be a need to separate political interests from the activities of the bureaucracy. The bureaucracy should be allowed to come up with policies in line with the constitution and following up the implementation in line with the legal requirements. 


\section{RECOMMENDATION}

In order for the devolved system of government in Kenya to facilitate efficient, effective and prudent delivery of services to the citizenry at the grassroots, the following strategic issues must be adequately addressed: better planning; strengthen the performance management framework; improvement in quality of County leadership; prioritization of investment in thematic areas based on comparative advantage; strengthening public participation in project identification, planning and execution; intensifying financial resource-mobilization; improved governance framework to facilitate prudent utilization of resources and enforcing accountability at all levels; rationalization of staffing levels; institutional capacity building; determining relevant training needs and corresponding staff training requirement; eradicating duplicity of effort; massive sensitization of both leaders and the citizens on relevant pieces of legislation supporting devolution; attitudinal and culture change programs; strengthening monitoring, evaluation and reporting frameworks; enhanced strategic alliances and partnerships; effective management of resistance to change; and benchmarking with best-case examples globally.

In this regard, there is need to conduct studies in each of the forty seven counties to establish which among the above strategic issues may be making them not deliver services as envisaged in the constitution.

\section{References}

Agor, W. H. (1989): Intuition in Organizations. Sage Publishing, New Park (CA)

Band, W. (1991): Creating Value for Customers. John Wiley and Sons, New York

Beitz, W. (1993): Designing for Ease of Recycling. Journal of Engineering Design vol. 4 No. 1, pp.11-23

Bisoux, T (2005): “What Makes Leaders Great?” BizEd Magazine pp. 40-45, September-October

Blake, Robert \& McCause, A. (1991): Leadership Dilemmas - Grid Solutions. Gulf Publishing, Houston

Caudron, S. (1995): “Delegate for Results”. Industrial Week, Feb. 6, pp 27-28

Cole, G. (1991): Management: Theory and Practice. DP Publications, London

Deal, T. \& Kennedy, A. (1988): Corporate Cultures. Penquin Books, NY

Drucker, P. (1988): “Leadership: More Doing than Dash”. The Wall Street Journal, Jan 6.

Fielder, F. E. (1992): Time Based Measures of Leadership Experience \& Organizational Performance".Leadership Quarterly, Spring, pp. 5-6

GoK (2010): The Constitution of Kenya. The Government Printer, Nairobi

GoK (2012): The County Governments Act. The Government Printer, Nairobi

GoK (2011): The Urban Areas and Cities Act. The Government Printer, Nairobi

GoK (2012): The Transition to Devolved Government Act. The Government Printer, Nairobi

GoK (2012): The Public Finance Management Act. The Government Printer, Nairobi

GoK (2013): The National Government Co-ordination Act. The Government Printer, Nairobi

Harrison, R. (1972): How to Describe your Organization. Harvard Business Review, Sept.-Oct.

Hand, C (1993): Understanding the Organization. Penguin Books Ltd, London

Hersey, P. \& Blanchard, K. H. (1988): Management of Organizational Behaviour. Prentice Hall, Englewood, Cliff, NJ 
Herzber, F. (1968): “One More Time: How do You Motivate Employee?” Harvard Business Review, vol. 47, January February, pp.54-63

Hogarth, R. H., Kahneman, D. and Treversky, A. (1994): Judgements in Managerial Decision Making (3rd Edition), John Wiley \& Sons, NY.

Huber, G. P. (1975): Managerial Decision Making. Scott-Foresman, Glenview.

Katz, R. L. (1974): Skills of an Effective Administrator. Harvard Business Review, Sept.-Oct. pp. 90-102

Locke, E. A. (1968): Toward a Task of Motivation and Incentives. Organizational Behaviour and Human Performance, May. Pp. 157-189

McCleland, D. C. (1961): The Achieving Society. Van Norstrand, NY

Mugore, J. L. M. (2015): UNDP Devolution Pillars and Lessons Learnt. MugoreAssociates, 15216 Eden Rock Court, Darnestown MD 20874 USA.

Oakland, J. (1993): Total Quality Management. Butterworth-Heinemann, NY

O’Reilley, C., Chatman, J. \& Caldwel, D. (1991): People and Organization Culture: A Profile Comparison Approach to Assessing Person-Organization Fit. Academy of Management Journal, Sept. pp.487-516

Paund, W. (1969): The process of Problem Finding. Industrial Management Review, Fall, pp. 11-12

Robbins, S. P. \& Hunsacker, P.L. (1996): Training in Interpersonal Skills (2nd Edition).Prentice Hall, Saddle River, NJ

Scott, J. T. (2008): The Entrepreneur's Guide to Building a Successful Business. Management Education Services, Panama Coty, Florida

Scott, J. T. (2005): The Concise Handbook of Management. Haworth Press, NY

Schein, E. (1990): Organizational Culture. American Psychologist, vol. 45 pp. 109-117

Simon, H. A. (1947): Administrative Behaviour. Free Press. NY. 